Check for updates

Cite this: RSC Adv., 2019, 9, 39011

\title{
A low-cost and scalable process for harvesting microalgae using commercial-grade flocculant $\dagger$
}

\author{
Gargi Goswami, $\neq^{a}$ Ratan Kumar, $\neq^{a}$ Ankan Sinha, (D) $\ddagger^{a}$ Soumen Kumar Maiti, ${ }^{a}$ \\ Babul Chandra Dutta, ${ }^{\mathrm{b}}$ Harendra Singh ${ }^{\mathrm{b}}$ and Debasish Das (D) *a
}

\begin{abstract}
A low-cost and scalable harvesting process was demonstrated for Chlorella sp. FC2 IITG, which offered an improved process economy for the production of a microalgal biomass feedstock via (i) the utilization of a cheaper commercial grade chemical flocculant; (ii) the recycling of post-harvested nutrient-rich spent water for the successive growth of the FC2 cells and (iii) the modulation of the flocculant dose, resulting in the non-requirement of a $\mathrm{pH}$ adjustment of the spent water and separate inoculum development step. Ferrous sulphate and ferric chloride were screened from a pool of four commercial grade flocculants, resulting in high harvesting efficiencies of $99.83 \%$ and $99.93 \%$ at the lower flocculant doses (g of flocculant $\mathrm{g}$ of dry biomass ${ }^{-1}$ ) of 2.5 and 3, respectively. The effect of the recycled nutrient-rich spent water and treated non-flocculated microalgal cells after harvesting was evaluated for the growth performance of the FC2 cells in six successive batches. It was found that ferrous sulphate was superior over ferric chloride in terms of the recyclability of the spent water for more number of batches, offering similar growth kinetics and nutrient recovery efficiency as compared with that of the control sample. The scale-up feasibility of the harvesting process was evaluated with a $5 \mathrm{~L}$ photobioreactor under indoor conditions and a $350 \mathrm{~L}$ open raceway pond under outdoor conditions with a modulated flocculant dose of $1.5 \mathrm{~g}$ ferrous sulphate. $\mathrm{g}$ dry biomass ${ }^{-1}$. The harvesting cost of $1 \mathrm{~kg}$ biomass using commercial grade ferrous sulphate was estimated to be in the range of 0.17-0.3 USD and was significantly lower as compared to that of analytical grade ferrous sulphate.
\end{abstract}

Received 5th October 2019

Accepted 11th November 2019

DOI: $10.1039 / c 9 r a 08072 d$

rsc.li/rsc-advances biomass concentration and productivity and (ii) the cost and energy-intensive harvesting technology. ${ }^{3,4}$ The dewatering or harvesting of algal cells, drying, cell disruption, and transesterification for converting algal lipids into biodiesel are the major cost-consuming steps, among which harvesting alone consumes $20-30 \%$ of the total project cost., ${ }^{5,6}$ In recent years, scientists have witnessed a significant advancement in research towards increasing the biomass concentration and productivity via process engineering strategies, novel photobioreactor designs, screening of robust strains or metabolic engineering of key biosynthetic pathways., ${ }^{5,78}$ However, very little progress has been made towards developing cost and energy-harvesting methods that can be implemented in large-scale cultivation.

The high cost and energy consumption of microalgal biomass are attributed to two key factors: (i) the small cell size and (ii) very low cell density $\left(<0.5 \mathrm{~g} \mathrm{~L}^{-1}\right){ }^{9-11}$ Furthermore, the viability of the harvesting method to be implemented at a large scale depends on several other factors, such as the type, value, and properties of the targeted product as well as cell viability and recycling of the culture medium. The existing technologies for microalgal harvesting can be broadly classified into four categories: physical, chemical, biological, and electrochemicalbased methods. Physical methods include centrifugation, gravity sedimentation, filtration, and flotation. While gravity
${ }^{a}$ Department of Biosciences \& Bioengineering, Indian Institute of Technology, Guwahati, Assam 781039, India. E-mail: debasishd@iitg.ac.in; debasish.iitg@gmail. com; Fax: +91-361-258-2249; Tel: +91-361-258-2221

${ }^{b}$ Institute of Biotechnology \& Geotectonic Studies, ONGC Ltd, A\&AA Basin, Cinnamara, Jorhat, Assam 785704, India

$\dagger$ Electronic supplementary information (ESI) available. See DOI: 10.1039/c9ra08072d

\$ Equal author contribution. 
sedimentation and flotation are used for pre-concentrating the biomass from a dilute solution of $0.5 \mathrm{~g} \mathrm{~L}^{-1}$ to a slurry of $10-50 \mathrm{~g}$ $\mathrm{L}^{-1}$, centrifugation and filtration are used mainly for a highly concentrated algal paste. These physical methods are reported to exhibit a wide variation in the percentage recovery of biomass depending on the initial culture concentration, and they have their own set of advantages or disadvantages. ${ }^{12}$ However, the requirements of a high amount of energy and long harvesting time are the major limitations of the physical methods; these limitations are further amplified when dewatering large volumes of microalgal cultures. Biological methods of harvesting (auto-flocculation and bio-flocculation), on the other hand, offer several advantages over physical and chemical methods; for example, they do not require any chemicals, they need lower power consumption, and they do not appear to interfere with the extraction of lipids from microalgae. ${ }^{9}$ The process of autoflocculation happens naturally based on the changes in the physicochemical parameters such as $\mathrm{pH}$, light intensity, limited $\mathrm{CO}_{2}$ supply or the presence of extracellular metabolites. ${ }^{13}$ In contrast, bio-flocculation can be achieved with the secreted biopolymers (exopolysaccharides) from the introduced microbes (bacteria or fungi) in the microalgal culture, which can help flocs aggregate faster than microalgae alone owing to their larger size. ${ }^{12}$ However, biological methods also offer various limitations: the presence of bacteria or other microalgae demands different growth conditions along with nutritional requirements; they may interfere with the food or feed applications due to contamination, and they are time-consuming. ${ }^{14}$ Although electrochemical-based harvesting also offers various advantages, the key limitation of the rising energy consumption with the increase in current density makes the process economically infeasible. ${ }^{6}$

Chemical flocculation is considered to be a prominent harvesting method, which can effectively process large volumes of microalgal culture and can be applied to a wide variety of species..$^{15}$ Flocculation by chemical agents is a phenomenon in which the cells in the suspension culture are settled as flocs or slurries by different types of flocculants via one of the following mechanisms: charge neutralization, patch coagulation, bridging, or sweep flocculation..$^{13}$ High biomass recovery efficiency has been reported for various chemical flocculants. For example, the biomass recovery efficiency was $96-98 \%$ when ferric sulphate was applied to Chlorella sorokiniana and Scenedesmus obliquus, ${ }^{16,17}$ and it was $90-98 \%$ when ferric chloride was applied to Chlorococcum sp. and Chlorella consortium; ${ }^{10}$ moreover, the value was $95 \%$ when aluminium sulphate was applied to Anabaena sp. and Asterionella sp. ${ }^{10}$ While most of these studies have been carried out with analytical grade chemical flocculants, studies on the application of commercial grade chemical flocculants are sparse in the literature. To date, some studies have investigated commercial grade flocculants; for instance, the coagulation-flocculation technique has been demonstrated for the harvesting of the microalga Chlamydomonas reinhardtii using chitosan and ten different commercial grade flocculants. ${ }^{18}$ The effects of $\mathrm{pH}$, salinity, biomass concentration, and algal organic matter on the efficiency of four commercial cationic flocculants were investigated for the harvesting of freshwater Chlorella vulgaris and marine Nannochloropsis oculata. ${ }^{19}$ Due to the high cost of analytical grade flocculants, the suitability of their application for the processing of biomass at a large scale remains impractical. Another key limitation of chemical flocculation is that the metal cations associated with the floc might deteriorate the biomass quality, which in turn may have a significant impact on the quality of the end product. However, the issue of metal contamination may be more relevant for high-value end products (food or feed) rather than bulk chemicals such as biofuels. ${ }^{20}$ Furthermore, a reliable, low-cost water supply is critical to the success of biofuel production from microalgae and therefore, recirculating nutrient-rich spent water after harvesting is a prerequisite to reduce water consumption and nutrient loss without compromising the growth performance of microalgae. Currently, the majority of the harvesting methods reported in the literature have been conducted under small-scale laboratory conditions. ${ }^{10,16,17}$ Hence, additional studies must be undertaken to check their performance under large-scale outdoor conditions.

This study presents a low-cost and scalable chemical flocculation-based harvesting method for microalgae Chlorella sp. FC2 IITG (hereafter referred to as FC2 cells). The strain has been found to be a potential candidate for biodiesel production $^{21}$ and hence, it has been considered for the present study. The economic feasibility of the process was targeted to be achieved via the utilization of cheaper commercial grade flocculants and the recycling of post-harvested spent water with unused nutrients for the growth of the FC2 cells in consecutive batches. Four commercial grade flocculants, namely, ferric chloride $\left(\mathrm{FeCl}_{3}\right)$, alum $\left(\mathrm{KAl}\left(\mathrm{SO}_{4}\right)_{2}\right)$, calcium hydroxide $\left(\mathrm{Ca}(\mathrm{OH})_{2}\right)$, and ferrous sulphate $\left(\mathrm{FeSO}_{4}\right)$ were considered for the initial characterization based on their harvesting performance. In the first step, the screening of suitable flocculating agent(s) was performed with the primary objective of the maximization of harvesting efficiency via the optimization of two key parameters: the ratio of the weight of the flocculant $(F)$ to the weight of the microalgal biomass $(X)(F / X)$ and the harvesting time. Furthermore, the suitability of the optimal harvesting parameters as a function of harvesting efficiency for the selected flocculants $\left(\mathrm{FeCl}_{3}\right.$ and $\left.\mathrm{FeSO}_{4}\right)$ was evaluated at different biomass concentrations. In the next step, with the aim of reducing the overall biomass production cost, both flocculants $\left(\mathrm{FeCl}_{3}\right.$ and $\mathrm{FeSO}_{4}$ ) were investigated for their individual effect on reclaiming post-harvested spent water and the use of harvested microalgal FC2 cells as an inoculum for subsequent cultivation. Finally, the feasibility of the harvesting method was demonstrated in a $5 \mathrm{~L}$ automated photobioreactor under indoor conditions and a $350 \mathrm{~L}$ open raceway pond under outdoor conditions using commercial grade $\mathrm{FeSO}_{4}$ as the flocculating agent. In addition, the evaluation of the possible effect of $\mathrm{FeSO}_{4}$ on cell morphology and cell viability was carried out using microscopic analysis and flow cytometry analysis. The mechanism of the $\mathrm{FeSO}_{4}$-based flocculation of algal biomass was determined using zeta potential. A detailed cost analysis was carried out to compare the costs of harvesting using commercial grade and analytical grade $\mathrm{FeSO}_{4}$. 


\section{Materials and methods}

\section{Microalgal strain and cultivation}

The microalgal strain FC2 used in the present study was isolated from a freshwater lake of North-East India; moreover, it has been characterized extensively for biodiesel production. ${ }^{22}$ The strain was cultivated in the optimized BG11 medium comprising $\left(\mathrm{g} \mathrm{L}^{-1}\right)^{22} \mathrm{MgSO}_{4} \cdot 7 \mathrm{H}_{2} \mathrm{O}, 0.124 ; \mathrm{CaCl}_{2} \cdot 2 \mathrm{H}_{2} \mathrm{O}, 0.065$; $\mathrm{Na}_{2} \mathrm{CO}_{3}, 0.038$; citric acid, 0.002; ferric ammonium citrate, 0.01; EDTA, 0.001; and an A5+Co solution $\left(1 \mathrm{~mL} \mathrm{~L}^{-1}\right)$ that consisted of $\mathrm{H}_{3} \mathrm{BO}_{3}, 2.86 ; \mathrm{MnCl}_{2} \cdot \mathrm{H}_{2} \mathrm{O}, 1.81 ; \mathrm{ZnSO}_{4} \cdot 7 \mathrm{H}_{2} \mathrm{O}$, 0.222; $\mathrm{CuSO}_{4} \cdot 5 \mathrm{H}_{2} \mathrm{O}, 0.079 ; \quad \mathrm{Na}_{2} \mathrm{MoO}_{4} \cdot 2 \mathrm{H}_{2} \mathrm{O}, 0.390 ;$ and $\mathrm{Co}\left(\mathrm{NO}_{3}\right)_{2} \cdot 6 \mathrm{H}_{2} \mathrm{O}, 0.049$ supplemented with commercial grade urea, 1.8; muriate of potash, 0.23 ; and single superphosphate, 0.076. For the initial optimization and characterization experiments, biomass was generated via the cultivation of the strain in a 7.5 L automated bioreactor (New Brunswick TM Bioflo® 115, Eppendorf, Germany) with a working volume of $5 \mathrm{~L}$. The evaluation of the effect of recycling post-harvested spent water on the growth of the FC2 cells was carried out in $500 \mathrm{~mL}$ bubble column mini reactors (Spectrochem Instruments Pvt. Ltd., India) with a working volume of $350 \mathrm{~mL}$. The demonstration of the scale-up feasibility of the harvesting method with the recycling of spent water was carried out by growing the strain in a $7.5 \mathrm{~L}$ automated bioreactor (New Brunswick TM Bioflo ${ }^{\circledR}$ 115, Eppendorf, Germany) with a working volume of $5 \mathrm{~L}$ under indoor conditions and a $500 \mathrm{~L}$ open raceway pond (length: $144 \mathrm{~cm}$, width: $144 \mathrm{~cm}$, and depth: $30 \mathrm{~cm}$ ) with a working volume of $350 \mathrm{~L}$ under outdoor conditions (Spectrochem Instruments Pvt. Ltd., India). All the cultivation experiments in the reactors were carried out at $28{ }^{\circ} \mathrm{C}, 300 \mathrm{rpm}$ and a light intensity of $250 \mu \mathrm{E} \mathrm{m} \mathrm{m}^{-2} \mathrm{~s}^{-1}$ with a light : dark cycle of $16: 8 \mathrm{~h}$. Cool fluorescent lamps of $25 \mathrm{~W}$ each (Ecolux $25 \mathrm{~W}$, Bajaj Electricals, India) were used as the

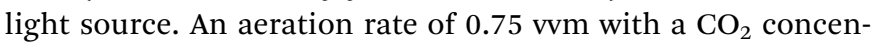
tration of $10 \%(\mathrm{v} / \mathrm{v})$ was used. For the open raceway pond, the inoculum preparation was carried out in $20 \mathrm{~L}$ transparent plastic bottles and culture from the mid log phase was transferred to the pond to achieve an initial OD of 0.2 at $690 \mathrm{~nm}$. The rotational speed of the paddle wheel was maintained at $150 \mathrm{rpm}$ throughout and the evaporation loss was compensated on a regular basis. During the entire cultivation period of the open pond, the sunlight hours and the temperature varied in the range of $10-12 \mathrm{~h}$ and $22-28{ }^{\circ} \mathrm{C}$, respectively.

\section{Screening of flocculating agent(s) via optimization of the $F / X$ ratio (the weight of the flocculant $F$ to the weight of the microalgal biomass $X$ ) and harvesting time}

A detailed representation of the experimental steps is shown in Fig. S1, ESI. $\dagger$ Initially, four commercial grade chemical flocculants were considered for the present study: $\mathrm{FeCl}_{3}$, $\mathrm{KAl}\left(\mathrm{SO}_{4}\right)_{2}, \mathrm{Ca}(\mathrm{OH})_{2}$, and $\mathrm{FeSO}_{4}$. These flocculants were donated by Bharat Trading Corporation, India. Suitable flocculants were selected based on their maximum harvesting efficiency. Therefore, in order to obtain the maximum harvesting efficiency for each flocculant, two parameters, i.e., (i) the ratio of the weight of the flocculant $(F)$ to the weight of the microalgal biomass $(X)(F / X)$ and (ii) harvesting time (after the addition of the flocculant) were optimized for the individual flocculant using a one-factor-at-a-time method. In the first step, the evaluation of the harvesting efficiency was carried out at an initial FC2 cell biomass concentration of $0.25 \mathrm{~g} \mathrm{~L}^{-1}$ for a harvesting time of $60 \mathrm{~min}$ with different $F / X$ ratios ranging from 0.5 to four consecutive values of the $F / X$ ratio, with an increment of 0.5 , resulting in constant harvesting efficiency. In the next step, the effect of the harvesting time was evaluated with different harvesting times ranging from $10 \mathrm{~min}$ to four consecutive values of the harvesting time, with an increment of $10 \mathrm{~min}$, resulting in constant harvesting efficiency. In the subsequent experiments, the $F / X$ ratio was fixed at the optimal value obtained from the previous step, and the initial biomass concentration was maintained at $0.25 \mathrm{~g} \mathrm{~L}^{-1}$. All the optimization experiments were carried out with $40 \mathrm{~mL}$ of culture broth in $50 \mathrm{~mL}$ conical centrifuge tubes. After the addition of the respective flocculant, a vortex mixing of $30 \mathrm{~s}$ was carried out to ensure proper mixing. For each experiment, at the end of the harvesting time, the sample was withdrawn from a height of $25 \%$ of the total sample height starting from the base of the tube without disturbing the settled biomass. All experiments were conducted in triplicates and the values are represented as mean \pm standard error. The harvesting efficiency (HE, \%) was calculated as follows:

$$
\mathrm{HE}(\%)=\frac{\mathrm{OD}_{\mathrm{i}}-\mathrm{OD}_{\mathrm{f}}}{\mathrm{OD}_{\mathrm{i}}} \times 100
$$

Here, $\mathrm{OD}_{\mathrm{i}}$ and $\mathrm{OD}_{\mathrm{f}}$ are the optical densities of the microalgal culture before harvesting and the supernatant liquid after harvesting, respectively. $\mathrm{FeCl}_{3}$ and $\mathrm{FeSO}_{4}$ were chosen for the subsequent characterizations based on the criteria of maximum harvesting efficiency with lower flocculant loading ( $F / X$ ratio) at the respective optimal values of harvesting time. All harvesting experiments were performed in triplicates and the values are represented as mean \pm standard error.

\section{Evaluation of suitability of optimal $F / X$ ratio and harvesting time for the selected flocculants at different biomass concentrations}

$\mathrm{FeCl}_{3}$ and $\mathrm{FeSO}_{4}$ were chosen based on the optimization studies performed with an initial biomass concentration of $0.25 \mathrm{~g} \mathrm{~L}^{-1}$. However, the biomass concentration in the culture broth may vary over a wide range depending on the growth conditions and cultivation systems. Therefore, it was important to test whether the respective optimal values of the $F / X$ ratio and harvesting time for the selected flocculants will be valid for a wide concentration range of the biomass in the broth. The harvesting efficiencies of $\mathrm{FeCl}_{3}$ and $\mathrm{FeSO}_{4}$ were evaluated at their respective optimal values of the $F / X$ ratio and harvesting time (obtained from the previous step) by varying the biomass concentration from $0.25 \mathrm{~g} \mathrm{~L}^{-1}$ to $3 \mathrm{~g} \mathrm{~L}^{-1}$ with an increment of $0.25 \mathrm{~g} \mathrm{~L}^{-1}$ (Fig. 1). The harvesting experiments were conducted as detailed in the preceding section. All the harvesting experiments were performed in triplicates and the values have been represented as mean \pm standard error. 

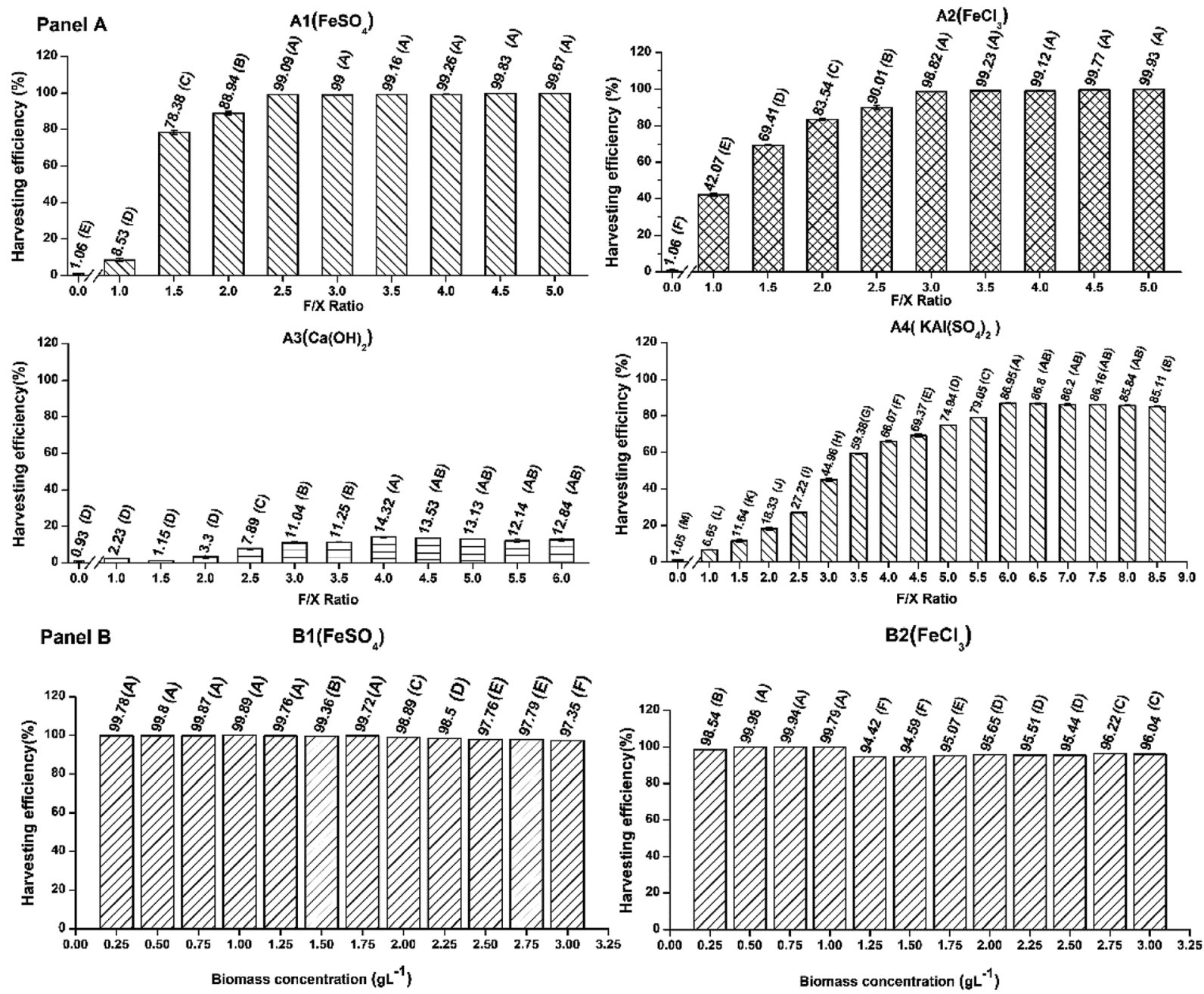

Fig. 1 Panel A - effect of flocculant dose (F/X ratio, $\mathrm{g}$ of flocculant $\mathrm{g}$ of dry biomass ${ }^{-1}$ ) on the harvesting efficiency of Chlorella sp. FC2: (A1) $\mathrm{FeSO}_{4},(\mathrm{~A} 2) \mathrm{FeCl}_{3},(\mathrm{~A} 3) \mathrm{Ca}(\mathrm{OH})_{2}$, and (A4) KAl(SO$)_{2}$. Panel B-effect of biomass concentration in the culture broth on the harvesting efficiency of Chlorella sp. FC2: (B1) $\mathrm{FeSO}_{4}$ and (B2) $\mathrm{FeCl}_{3}$. In Panel A, all experiments were conducted with an initial biomass concentration of $0.25 \mathrm{~g} \mathrm{~L}^{-1}$. In Panel $\mathrm{B}, \mathrm{F} / \mathrm{X}$ ratios of 2.5 and 3 were used for $\mathrm{FeSO}_{4}$ and $\mathrm{FeCl}_{3}$, respectively. All experiments were conducted in triplicate and the data were expressed as mean \pm standard error. The letters on the bar graphs represent the significant differences in the harvesting efficiencies obtained from harvesting microalgal biomass using different flocculants with different $F / X$ ratios, and the biomass concentration was analyzed using oneway analysis of variance based on the Tukey's method. Harvesting efficiencies that do not share a common letter are significantly different.

Effect of recycling culture medium and harvested FC2 cells on the growth of FC2 cells and harvesting efficiency

Both selected flocculants, $\mathrm{FeCl}_{3}$ and $\mathrm{FeSO}_{4}$, were investigated for their individual effect on the reclaiming of post-harvested spent water and use of harvested microalgal FC2 cells as an inoculum for subsequent cultivations (Fig. S1, ESI $\dagger$ ). For any particular flocculant, two sets of experiments were conducted in mini-reactors. Each set of experiment comprised six consecutive batches. In each set, the first batch with a fresh medium and fresh FC2 cells as the inoculum was considered as the control batch, and the successive five batches were considered as recycled batches. In one set of experiments, the growth characterization was carried out with the recycling (R) of spent water (W) after harvesting and fresh (F) FC2 cells (C) as the inoculum for the five successive recycled batches (designated as the RWFC batch). In another set of experiments, five batch runs were carried out with recycled (R) spent water (W) after harvesting from the previous batch but with harvested (H) FC2 cells (C) as the inoculum for the consecutive batches (designated as the RWHC batch). The RWHC batches were set up with the aim of assessing any possible detrimental effect of the flocculant on the cell growth. Every individual batch was continued until the biomass concentration attained a value of $\sim 1-1.15 \mathrm{~g} \mathrm{~L}^{-1}$, followed by harvesting the biomass. After harvesting the biomass at the end of each batch cycle, the $\mathrm{pH}$ of the culture medium was adjusted to a value of 7.1-7.4. Prior to the use of the recycled spent water in the next batch, the concentrations of urea and phosphate were adjusted to their respective optimal values in the optimized BG11 medium. A dynamic profile of the growth (in terms of biomass concentration) of the FC2 cells in each batch was obtained via analysis of the sample collected at an interval of $8 \mathrm{~h}$. The harvesting experiments were carried out in 
$500 \mathrm{~mL}$ glass beakers. After the addition of the respective flocculant, homogeneous mixing was achieved using a magnetic stirrer (IKA C-MAG, India) at $100 \mathrm{rpm}$ for $30 \mathrm{~s}$. The harvesting efficiency was calculated as explained in the previous section. Based on the improved growth performance of the FC2 cells in terms of the biomass productivity, harvesting efficiency, and urea recovery in six consecutive batches, $\mathrm{FeSO}_{4}$ was finally selected for the demonstration of the harvesting process at a higher scale of cultivation.

The biomass productivity $\left(P, \mathrm{mg} \mathrm{L}^{-1} \mathrm{day}^{-1}\right)$ was calculated based on the following eqn (2):

$$
P=\frac{X_{\mathrm{f}}-X_{0}}{t_{\mathrm{f}}-t_{0}}
$$

Here, $X_{0}$ and $X_{\mathrm{f}}$ are the dry cell weights $\left(\mathrm{g} \mathrm{L}^{-1}\right)$ obtained at the initial and final time points, $t_{0}$ and $t_{\mathrm{f}}$, of cultivation, respectively.

The urea recovery (UR, \%) after harvesting was calculated as per the following eqn (3):

$$
\mathrm{UR}=\frac{U_{\mathrm{a}}}{U_{\mathrm{b}}} \times 100
$$

Here, $U_{\mathrm{b}}$ and $U_{\mathrm{a}}$ are the urea concentrations before and after harvesting the FC2 cells, respectively. Each set of experiments was performed in triplicates and the values are represented as mean \pm standard error.

\section{Demonstration of a low-cost harvesting method at the scaled- up conditions of a $5 \mathrm{~L}$ photobioreactor and $500 \mathrm{~L}$ open raceway pond}

A low-cost harvesting method with the recycling of spent water using commercial grade $\mathrm{FeSO}_{4}$ was demonstrated in a $5 \mathrm{~L}$ automated photobioreactor under indoor conditions in six consecutive batches (one control batch and five RWHC batches) with an optimal $F / X$ ratio of 2.5 and harvesting time of 50 min (Fig. S1, ESI $\dagger$ ). In the next step, the harvesting of microalgal biomass from the $5 \mathrm{~L}$ photobioreactor was carried out with a lower $F / X$ ratio of 1.5 in three consecutive batches (one control and two subsequent recycled batches). Recycled batch runs were carried out with recycled (R) spent water (W) after harvesting from the previous batch but with treated nonflocculated (NF) FC2 cells (C) as the inoculum for the consecutive batches (designated as the RWNFC batch). This lower flocculant dose was selected in such a way that the residual biomass in the spent media after harvesting can be used as the inoculum for the successive batch. The harvesting performance was finally evaluated in a $350 \mathrm{~L}$ open raceway pond under outdoor conditions with an $F / X$ ratio of 1.5 for two consecutive batches (one control batch and one RWNFC batch) (Fig. S1, ESI $\dagger$ ). The concentrations of urea and phosphate in the recycled spent water were adjusted to their respective optimal values before the initiation of every successive batch. The cultivation conditions in the bioreactor and open raceway pond were kept similar, as mentioned in the previous section. Every batch was terminated upon the attainment of a biomass concentration of $\sim 1-1.15 \mathrm{~g} \mathrm{~L}^{-1}$ for the photobioreactor and $\sim 0.3-0.7 \mathrm{~g} \mathrm{~L}^{-1}$ for the open raceway pond, followed by harvesting the FC2 cells. Sampling was performed at every $8 \mathrm{~h}$ time interval to obtain a dynamic profile of the growth of the FC2 cells. The harvesting experiments were carried out in a $5 \mathrm{~L}$ glass beaker and $20 \mathrm{~L}$ transparent plastic bottles for microalgal cultivation in a $5 \mathrm{~L}$ bioreactor and $350 \mathrm{~L}$ open raceway pond, respectively. For harvesting in a $5 \mathrm{~L}$ glass beaker, after the addition of the respective flocculant, homogeneous mixing was achieved using a magnetic stirrer (IKA C-MAG, India) at $100 \mathrm{rpm}$ for $30 \mathrm{~s}$. In the case of harvesting in a $20 \mathrm{~L}$ transparent bottle, mixing was achieved using mechanical agitation at $200 \mathrm{rpm}$ for $30 \mathrm{~s}$. Harvesting efficiency was calculated as explained in the previous section (eqn (1)). All experiments were performed in triplicates and the values are represented as mean \pm standard error.

\section{Effect of flocculation on cell morphology and cell viability}

Microscopic analysis. Microalgal FC2 cells, before and after harvesting, were observed under a brightfield microscope at $100 \times$ magnification (NIKON DS, Carl Zeiss, Germany). To capture the difference between the cell surfaces before and after harvesting, a Field Emission Scanning Electron Microscope (FESEM) (Gemini 300, Carl Zeiss, Germany) was used. The microalgal cell sample used for analysis was dried using the protocol described by Muthuraj et al. ${ }^{22}$ FESEM images were observed at an acceleration voltage of $2 \mathrm{kV}$ after gold coating (Evaporator, Bal-tec, Germany). The microalgal samples were then examined with a low-vacuum field emission scanning electron microscope (LV-FESEM) with energy-dispersive X-ray (EDX) spectroscopy. ${ }^{23}$

Flow cytometry analysis. The effect of the flocculant $\left(\mathrm{FeSO}_{4}\right)$ on cell viability was studied by means of the staining method using fluorescein diacetate (FDA). Aliquots $(1 \mathrm{~mL})$ containing 2 $\times 10^{5}$ FC2 cells were centrifuged, followed by resuspension in a $1 \mathrm{~mL}$ volume of phosphate buffered saline (PBS, $\mathrm{pH}$ 7.4). The cells in PBS were then stained with FDA at a final concentration of $50 \mathrm{ng} \mathrm{mL} \mathrm{m}^{-1}$ for $15 \mathrm{~min}$ at room temperature under dark conditions. ${ }^{24}$ Flow cytometry analysis of the stained cells was performed in a Coulter Epics XL4 flow cytometer (Beckman Coulter Inc., Fullerton, CA, USA) equipped with an argon-ion excitation laser (488 $\mathrm{nm}$ ), detectors of forward (FS) and side (SS) light scatter, and four fluorescence detectors corresponding to four different wavelength intervals: 505-550 nm (FL1), 550$600 \mathrm{~nm}$ (FL2), 600-645 $\mathrm{nm}$ (FL3), and >645 nm (FL4). The forward scatter and green chlorophyll fluorescence histograms were used to characterize the microalgal population. Gating levels were set in order to exclude non-microalgal particles. For each cytometry parameter investigated, at least $10^{4}$ gated cells were analyzed per culture, and the fluorescence measurements were obtained in a logarithmic scale. Data were collected using the list mode files and statistically analyzed using the inbuilt FlowJo (Beckman Coulter Inc.).

Measurement of the zeta potential of algal FC2 cells. The zeta potential (ZP) was determined for the microalgal culture using Malvern ZetaSizer ZS-90 (Malvern, UK) before adding any flocculant, settled biomass (after flocculation) and the spent media (after flocculation). 


\section{Analytical methods}

The cell density was obtained by measuring the absorbance at $690 \mathrm{~nm}\left(A_{690}\right)$ using a UV-Vis spectrophotometer (Cray $100 \mathrm{UV}$ Vis, Agilent Technologies, USA), and the dry cell weight was determined using its linear correlation with absorbance. Under a photoautotrophic condition, 1 cell density $\left(A_{690}\right)=0.275 \mathrm{~g}$ dry cells $\mathrm{L}^{-1}, 1.421 \leq A_{690} \leq 8.633\left(R^{2}=0.99\right)$. The concentrations of phosphate and urea in the broth were quantified by the ascorbic acid method and diacetyl monoxime method, respectively. ${ }^{25,26}$ The measurement of the iron (Fe) concentration in the post-harvested spent media was performed using a $4210 \mathrm{MP}$ Atomic Emission Spectroscopy (AES) spectrometer (Agilent Technologies). The plasma stabilization time was $15 \mathrm{~s}$, the number of sample injections was 3 , and the number of pixels for processing the analytical signals was 1 . Spectra were processed using the Agilent MP Expert software (ver. 1.5.2.7948). All the experiments were performed in triplicates and the values are represented as mean \pm standard error.

\section{Statistical analyses}

All experimental data were represented as the mean value with standard deviation (SD), and significant differences in comparative data were analyzed by performing the Tukey test through one-way analysis of variance (ANOVA).

\section{Results and discussion}

\section{Screening of flocculating agents via optimization of flocculant to biomass loading $(F / X$ ratio) and harvesting time}

Initially, four commercial grade inorganic chemicals were considered for the screening of suitable flocculants: $\mathrm{FeSO}_{4}$, $\mathrm{FeCl}_{3}, \mathrm{Ca}(\mathrm{OH})_{2}$, and $\mathrm{KAl}\left(\mathrm{SO}_{4}\right)_{2}$. These chemicals were chosen for further testing based on their harvesting performance for algal biomass, as demonstrated in various studies reported in the literature. ${ }^{10,27,28}$ The selection of suitable flocculating agent(s) was performed based on the criteria of maximum harvesting efficiency with a lower flocculant loading and minimum harvesting time via the optimization of two parameters: the $F / X$ ratio and harvesting time. It is important to mention that in most publications, the optimization of flocculation-based harvesting has been performed for the absolute flocculant dose per liter of culture medium. ${ }^{\mathbf{1 4 , 2 9}}$ However, the biomass concentration in the culture broth may vary over a wide range from $0.25 \mathrm{~g}$ $\mathrm{L}^{-1}$ to $5 \mathrm{~g} \mathrm{~L}^{-1}$ depending on the growth conditions, cultivation systems, and scales of operation. Therefore, it makes sense that the flocculant dose be optimized with respect to biomass $(F / X$ ratio) rather than per liter of the culture medium. The evaluation of the effect of the $F / X$ ratio on the harvesting efficiency revealed that for all the four flocculants, the harvesting efficiency increased with the increase in the $F / X$ ratio and reached a maximum at the $F / X$ ratios of $6,2.5,3$, and 4 for $\mathrm{KAl}\left(\mathrm{SO}_{4}\right)_{2}$, $\mathrm{FeSO}_{4}, \mathrm{FeCl}_{3}$, and $\mathrm{Ca}(\mathrm{OH})_{2}$, respectively, followed by no further change even with the increase in flocculant loading (Fig. 1). The maximum harvesting efficiencies for $\mathrm{KAl}\left(\mathrm{SO}_{4}\right)_{2}, \mathrm{FeSO}_{4}, \mathrm{FeCl}_{3}$, and $\mathrm{Ca}(\mathrm{OH})_{2}$ were found to be $86.9 \%, 99.83 \%, 99.93 \%$, and $14.32 \%$, respectively (Fig. 1). Due to the low harvesting efficiency of $\mathrm{Ca}(\mathrm{OH})_{2}$, the optimization of the harvesting time was carried out only for the remaining three flocculants. The optimization of the harvesting time resulted in a reduced processing time to $50 \mathrm{~min}$ and $40 \mathrm{~min}$ for $\mathrm{FeSO}_{4}$ and $\mathrm{FeCl}_{3}$, respectively, without compromising the harvesting efficiency (Fig. S2, ESI $\dagger$ ). In the case of $\mathrm{KAl}\left(\mathrm{SO}_{4}\right)_{2}$, a marginal improvement in the harvesting efficiency was observed at the cost of increased harvesting time to $70 \mathrm{~min}$. Inorganic salts such as $\mathrm{FeSO}_{4}, \mathrm{FeCl}_{3}$, and $\mathrm{KAl}\left(\mathrm{SO}_{4}\right)_{2}$ readily form metal hydroxides in water, which subsequently flocculate or coagulate algal biomass via charge neutralization, bridging or sweep flocculation. ${ }^{28}$ Based on these results, $\mathrm{FeSO}_{4}$ and $\mathrm{FeCl}_{3}$ were selected as suitable candidates for harvesting FC2 because they offered improved harvesting efficiency at a lower flocculant loading and minimum harvesting time. Similar to the present study, $\mathrm{FeCl}_{3}$ has been reported to recover biomass with an efficiency in the range of 90-99\% when applied to various microalgal strains, e.g., Chlorella sp., Scenedesmus sp., and Choricystis minor. ${ }^{\mathbf{1 0}, 28}$ However, in these studies, higher efficiency of biomass harvesting was achieved using a lower $F / X$ ratio (0.1-0.4) in comparison to the present study $(F /$ $X=3$ ). The reported higher harvesting efficiency at a lower $F / X$ ratio may be attributed to the utilization of an analytical grade flocculant as opposed to a commercial grade flocculant used in the present study. A lower harvesting efficiency of $59.9 \%$ was achieved when $\mathrm{FeSO}_{4}$ was used to recover Scenedesmus sp. at an $F / X$ ratio of $2 .^{30}$ It is important to note that the flocculation potential of microalgae depends on various strain-specific factors, e.g., the composition of the cell wall, type of metabolite excretion, and physiology of the cells. ${ }^{31}$ Therefore, the performance of a particular flocculant in terms of biomass harvesting may vary depending on the microalgal strains. We conclude that the utilization of the commercial grade flocculants $\mathrm{FeSO}_{4}$ and $\mathrm{FeCl}_{3}$ offers equivalent harvesting efficiencies as compared to the values reported in the literature albeit at a higher flocculant loading (Table 1).

\section{Effect of biomass concentration on harvesting efficiency}

From the point of view of the feasibility of scale-up and its application, irrespective of the concentration of the biomass in the culture broth, it was important to test the harvesting performance of the selected flocculants $\mathrm{FeSO}_{4}$ and $\mathrm{FeCl}_{3}$ with a variation in the biomass concentration. The experiment was performed with optimal $F / X$ ratios and harvesting times of 2.5 and $50 \mathrm{~min}$ and 3 and $40 \mathrm{~min}$ for $\mathrm{FeSO}_{4}$ and $\mathrm{FeCl}_{3}$, respectively. Among the two selected flocculants, the harvesting efficiency of $\mathrm{FeSO}_{4}$ remained uncompromised (97-99\%) even with the increase in biomass concentration up to $3 \mathrm{~g} \mathrm{~L}^{-1}$ (Fig. 1). In the case of $\mathrm{FeCl}_{3}$, a marginal decline in the harvesting efficiency was observed beyond a biomass concentration of $1 \mathrm{~g} \mathrm{~L}^{-1}$, maintaining a minimum harvesting efficiency of $\sim 95 \%$ until a biomass concentration of $3 \mathrm{~g} \mathrm{~L}^{-1}$ (Fig. 1). Therefore, both commercial grade $\mathrm{FeSO}_{4}$ and $\mathrm{FeCl}_{3}$ could offer similar harvesting efficiencies for FC2 up to a biomass concentration of $3 \mathrm{~g} \mathrm{~L}^{-1}$. These observations point towards the suitability of both $\mathrm{FeSO}_{4}$ and $\mathrm{FeCl}_{3}$ as potential flocculating agents that can be employed with different biomass concentrations. 


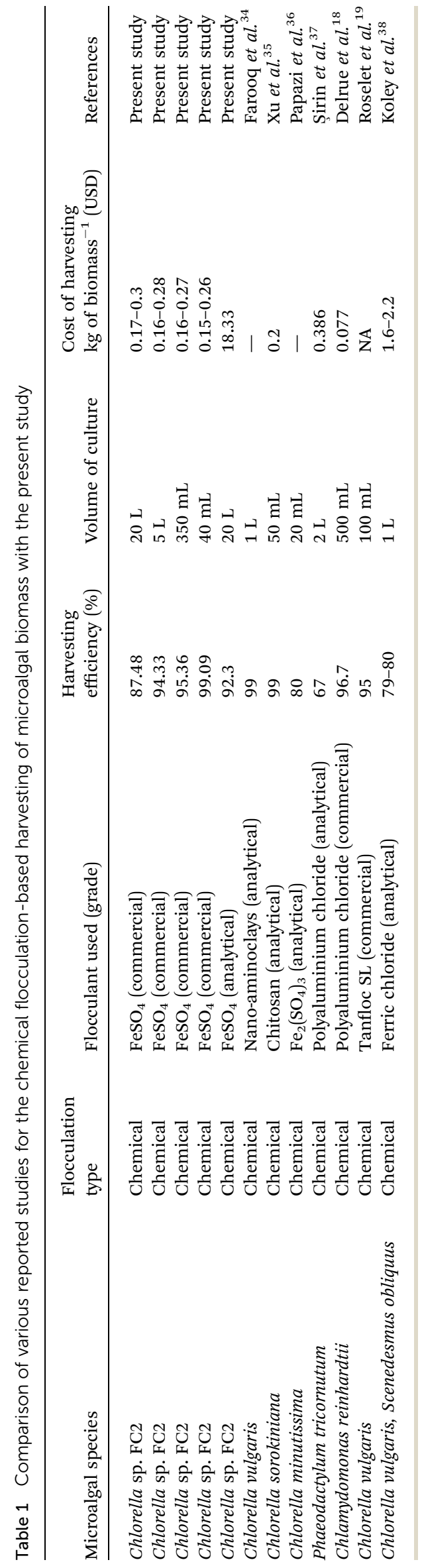

In a previous study, a linear correlation between the required flocculant dosage and the initial concentration of biomass was reported when $\mathrm{FeCl}_{3}, \mathrm{Al}_{2}\left(\mathrm{SO}_{4}\right)_{3}, \mathrm{KAl}\left(\mathrm{SO}_{4}\right)_{2}$, and chitosan were tested for Scenedesmus sp. ${ }^{27}$ However, in this study, the experiments were conducted only with a maximum biomass concentration of $0.66 \mathrm{~g} \mathrm{~L}^{-1}$. In another report, $\mathrm{FeCl}_{3}$-induced flocculation of Chlorella zofingiensis was studied over a biomass concentration range of 0.05-1.4 g $\mathrm{L}^{-1}{ }^{32}$ For a biomass concentration below $0.3 \mathrm{~g} \mathrm{~L}^{-1}$, the required flocculant dose was shown to vary linearly with the cell concentration in the broth, ensuring a harvesting efficiency of more than $90 \%$. However, for a biomass concentration above $0.3 \mathrm{~g} \mathrm{~L}^{-1}$, a fixed flocculant dose of $200 \mathrm{mg} \mathrm{L}^{-1}$ was required to achieve a minimum harvesting efficiency of $90 \%{ }^{32}$ Furthermore, the flocculation efficiencies of different doses of aluminium nitrate sulphate were examined with various cell concentrations of Nannochloropsis salina..$^{33}$ Even at a very high biomass concentration of $15-20 \mathrm{~g} \mathrm{~L}^{-1}$, stronger aggregation and sedimentation of the cells were observed at a flocculant dose of $10.8 \mathrm{mg} \mathrm{L}^{-1}$ or higher.

\section{Effect of recycling spent water and harvested FC2 cells as the inoculum on the growth performance of the FC2 cells, harvesting efficiency, and urea recovery}

In order to achieve better process economy, it is essential that nutrient-rich spent water be recycled after harvesting to reduce water consumption and nutrient loss without compromising microalgal growth. For both $\mathrm{FeSO}_{4}$ and $\mathrm{FeCl}_{3}$, five consecutive RWFC batch runs were conducted to evaluate the effect of post-harvested recycled water on the growth performance of the $\mathrm{FC} 2$ cells. In the case of $\mathrm{FeSO}_{4}$, a targeted biomass concentration of $\sim 1-1.15 \mathrm{~g} \mathrm{~L}^{-1}$ was achieved within $40 \mathrm{~h}$ of cultivation for the first two consecutive RWFC batches, depicting similar growth performances even with the recycled water. However, from the third RWFC batch onwards, the time required to achieve the targeted biomass concentration was found to increase with every successive batch, indicating a slower growth rate of the FC2 cells (Fig. 2). This observation was more prominent when the RWFC batches were compared with the control batch in terms of biomass productivity. Until the second RWFC batch for $\mathrm{FeSO}_{4}$, the biomass productivity was found to be within $90 \%$ of that of the control. However, the biomass productivity decreased significantly to $76 \%, 62 \%$, and $59 \%$ for the third, fourth, and fifth RWFC batches, respectively, when compared with that of the control (Fig. 3). In the case of $\mathrm{FeCl}_{3}$, a significant fall in biomass productivity (69\% of that of the control) and growth rate was observed in the first RWFC batch only (Fig. 2 and 3), followed by maintaining a constant productivity until the fourth batch. A further decline in the biomass productivity $(50 \%$ of that of the control) and growth rate was observed in the fifth RWFC batch (Fig. 2 and 3). The average biomass productivity of the five RWFC batches using the $\mathrm{FeSO}_{4}$-harvested recycled medium was calculated to be significantly higher (573 $\mathrm{mg} \mathrm{L}^{-1}$ day $^{-1}$ ) in comparison to that for $\mathrm{FeCl}_{3}$ 

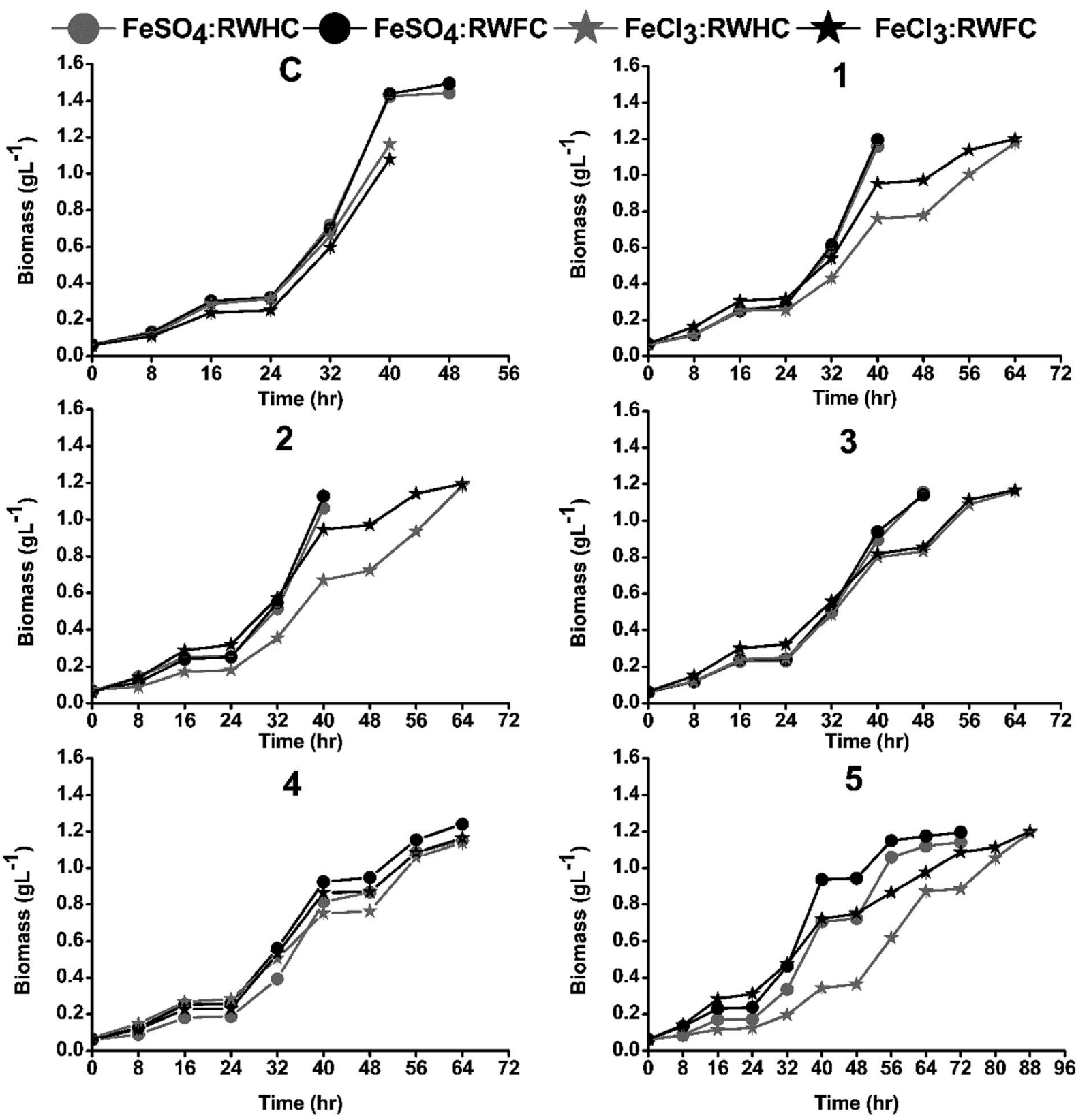

Fig. 2 Dynamic growth profile of Chlorella sp. FC2 in six consecutive batches of cultivation (one control (C), followed by five recycled batches (1-5)). The batch with fresh medium and fresh FC2 cells as the inoculum was considered as the control batch. RWFC represents the batches with the recycling of spent water and fresh FC2 cells as the inoculum for the successive batch. RWHC represents the batches with the recycling of spent water after harvesting and harvested FC2 cells as the inoculum for the successive batch. Harvesting experiments were performed with the microalgal biomass grown in mini-reactors with a working volume of $350 \mathrm{~mL}$. Harvesting experiments were performed with $\mathrm{FeSO}_{4}$ and $\mathrm{FeCl}_{3}$ with the $F / X$ ratios of 2.5 and 3 , respectively.

(420 $\mathrm{mg} \mathrm{L}^{-1}$ day $^{-1}$ ). Furthermore, five RWHC batches were set up for both the flocculants, where the harvested FC2 cells were used as the inoculum as opposed to fresh FC2 cells in the case of the RWFC batches. Every individual RWFC and RWHC batch exhibited similar growth profiles for both $\mathrm{FeSO}_{4}$ and $\mathrm{FeCl}_{3}$ (Fig. 3). Furthermore, a reduction in the biomass productivity, merely in the range of $1-5 \%$, was observed in the case of RWHC as compared to that for RWFC for both the flocculants (Fig. 3).
The results point towards no significant detrimental effect of these two flocculants on the FC2 cells. The growth of Scenedesmus sp. was shown to remain unaffected for up to two times recycling of the $\mathrm{FeCl}_{3}$-harvested culture medium. ${ }^{27}$ In a similar study, the growth performance and physiological state of aluminium nitrate sulphate-flocculated Nannochloropsis salina cells were shown to be similar to that of the non-flocculated cells grown in a fresh medium. ${ }^{33}$ Furthermore, better average 
Panel A - $\mathrm{FeSO}_{4}$

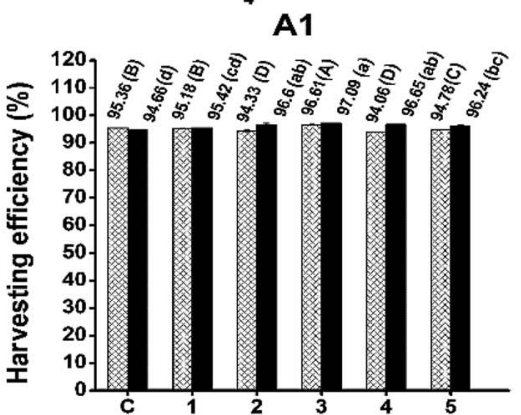

Panel B $-\mathrm{FeCl}_{3}$

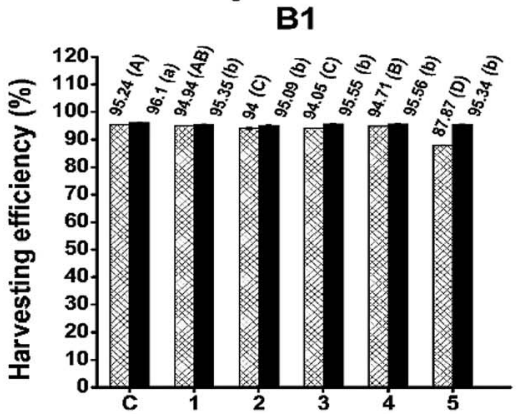

A2

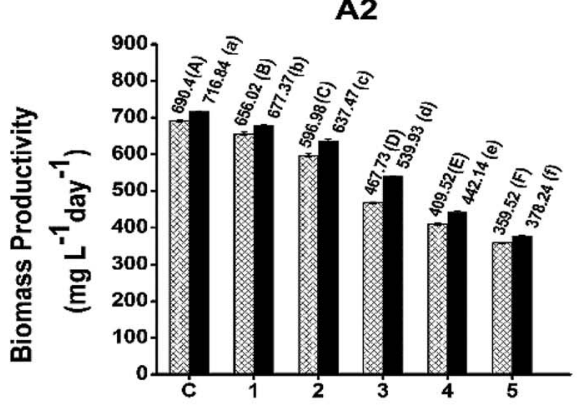

B2

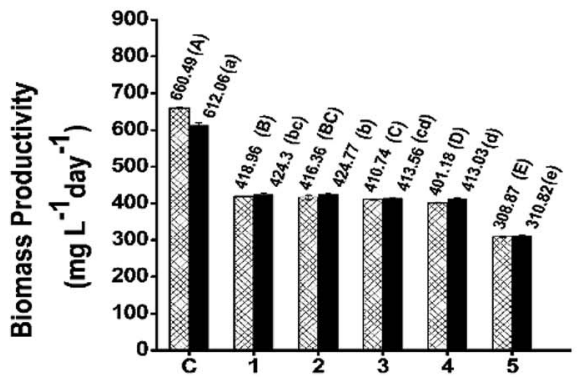

RWHC Batch RWFC Batch

A3

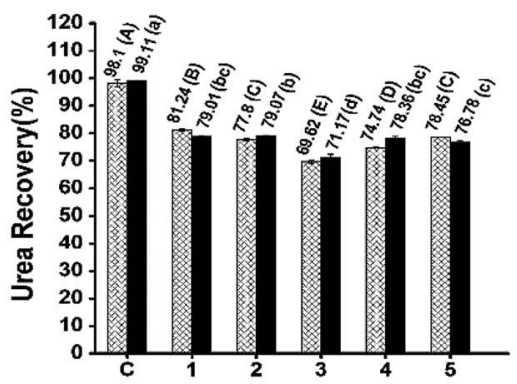

B3

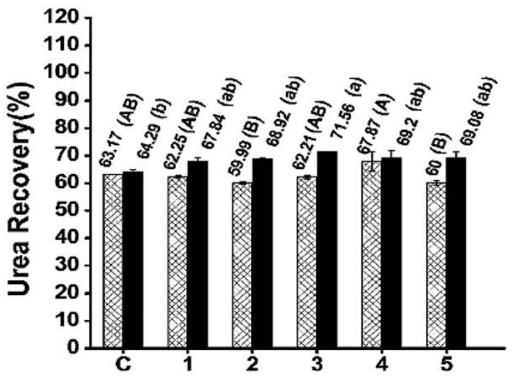

Fig. 3 Effect of recycling post-harvested spent water on the harvesting efficiency, biomass productivity and urea recovery for the growth of Chlorella sp. FC2 cells in six consecutive batches of cultivation (one control (C) followed by five recycled batches (1-5)). The batch with fresh medium and fresh FC2 cells as the inoculum was considered the control batch. RWFC represents the batches with the recycling of spent water after harvesting and fresh FC2 cells as the inoculum for the successive batch. RWHC represents the batches with the recycling of spent water after harvesting and harvested FC2 cells as the inoculum for the successive batch. Harvesting experiments were performed with the microalgal biomass grown in mini-reactors with a working volume of $350 \mathrm{ml}$. Harvesting experiments were performed with $\mathrm{FeSO}_{4}\left(\mathrm{Panel}^{\mathrm{A}}\right)$ and FeCl $3(\mathrm{Panel}$ B) with an F/X ratio of 2.5 and 3, respectively. The letters on the bar graphs represent the significant differences between the harvesting efficiency, biomass productivity, and urea recovery obtained from the harvesting of microalgal biomass using $\mathrm{FeSO}_{4}$ and $\mathrm{FeCl}_{3}$ analyzed using the one-way analysis of variance based on Tukey's method. Harvesting efficiency, biomass productivity and urea recovery that do not share a common letter are significantly different.

urea recoveries of $80.7 \%$ and $76.5 \%$ were achieved from five RWFC and RWHC batches, respectively, using the $\mathrm{FeSO}_{4}$-harvested recycled water as compared to those for $\mathrm{FeCl}_{3}(69 \%$ for RWFC and $62.4 \%$ for RWHC) (Fig. 3). No significant difference in the harvesting efficiencies was observed between the RWFC/ RWHC batches and the control batch for both the flocculants (Fig. 3). Furthermore, the analysis of the Fe concentration for both $\mathrm{FeSO}_{4}$ and $\mathrm{FeCl}_{3}$ revealed that $69.15 \%$ and $71.2 \%$ of the total $\mathrm{Fe}$ content used in the flocculation were retained in the post-harvested spent media, respectively. Out of the two selected flocculants, $\mathrm{FeSO}_{4}$ was finally chosen for further investigations based on its superior performance in terms of (i) the number of batches of reusability of the culture medium with an uncompromised growth performance, (ii) biomass productivity, (iii) growth rate, and (iv) urea recovery efficiency as compared to $\mathrm{FeCl}_{3}$.

\section{Effect of $\mathrm{FeSO}_{4}$ on cell morphology and cell viability}

In order to assess any possible detrimental effect of $\mathrm{FeSO}_{4}$ on cell morphology and cell viability, microscopic analysis and flow cytometry analysis were carried out with fresh FC2 cells and FC2 cells treated with $\mathrm{FeSO}_{4}$. Before harvesting, the fresh
FC2 cells exhibited a simple spherical outline with a homogeneous suspension in the culture media (Fig. 4A and C). Following the addition of $\mathrm{FeSO}_{4}$, the treated $\mathrm{FC} 2$ cells were found to form larger aggregates, resulting in the settling of biomass (Fig. 4B and D). Furthermore, the presence of no distinct rupture or damage to the cell wall was visually detected, suggesting no or minimal cell lysis upon treatment with the flocculant (Fig. 4E and F). When the cells are exposed to FDA, this non-fluorescent, non-polar, and lipophilic molecule diffuses across the cell membranes, followed by the cleavage of its acetate residues by non-specific esterases, resulting in the formation of fluorescein. While the viable cells with intact plasma membranes can retain this fluorescent product, rapid leakage of the dye takes place in the case of non-viable cells. Therefore, fluorescein fluorescence emission is used as an indicator of metabolic activity in the cell and indirectly also as a viability marker. The flow cytometry analysis of FDA-stained FC2 cells revealed that the treatment of algal cells with $\mathrm{FeSO}_{4}$ resulted in the loss of cell viability by merely $9 \%$, depicting an insignificant detrimental effect of the flocculant on the cell viability (Fig. 4G and $\mathrm{H}$ ). 

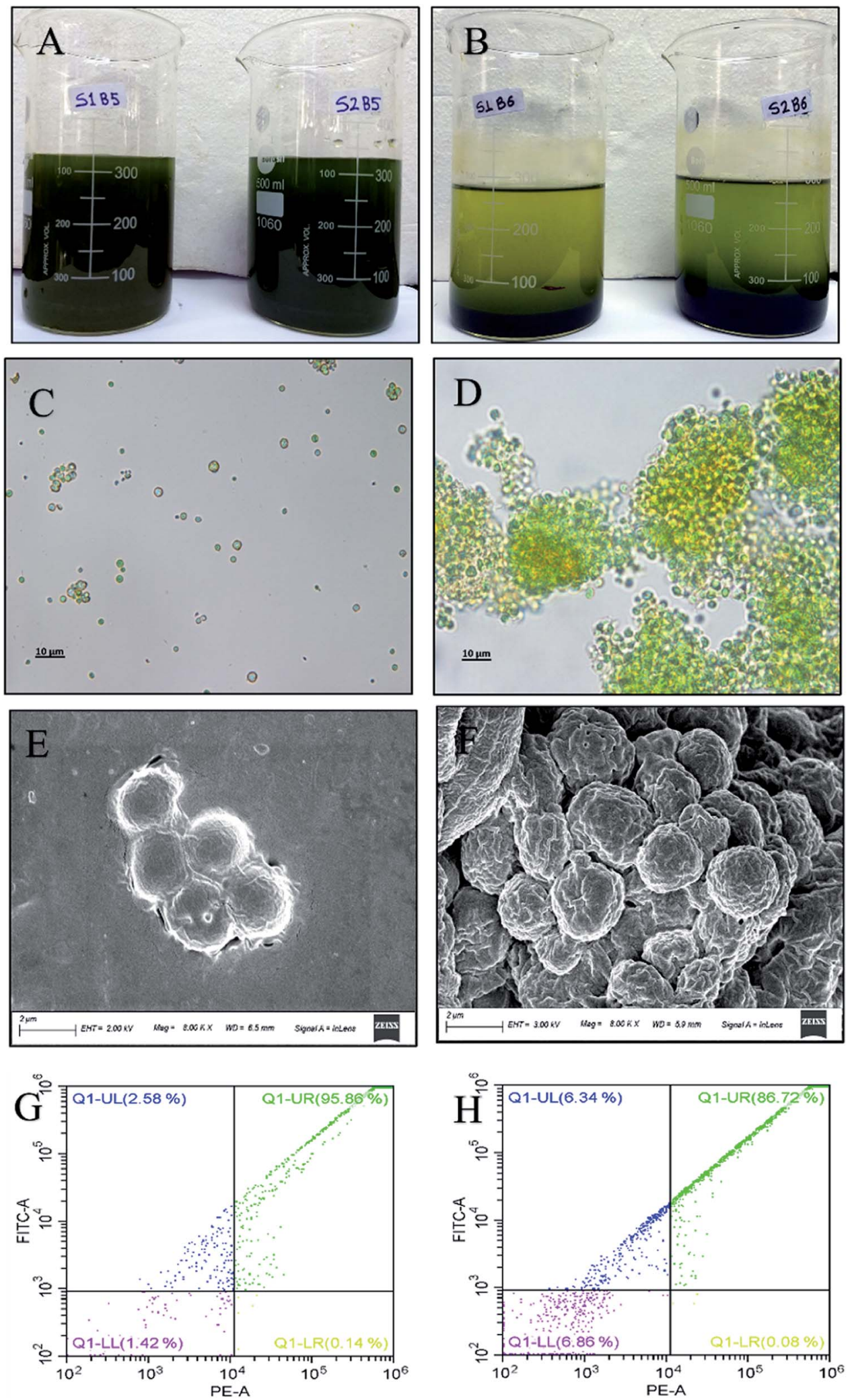

Fig. 4 Effect of the flocculant on the culture broth, cell morphology and cell viability. The left-hand side panel and right-hand side panel represent the states before and after harvesting with $\mathrm{FeSO}_{4}$. (A and $\mathrm{B}$ ) algal culture broth; (C and $\left.\mathrm{D}\right)$ cell morphology under a brightfield microscope (100× magnification); (E and F) cell morphology under FESEM (8k magnification); and ( $G$ and $H$ ) cell viability assessed through flow cytometry analysis. The harvesting experiment was carried out at $F / X$ of 2.5 and harvesting time of 50 min. 
Understanding the flocculation mechanism of Chlorella sp. FC2 IITG using $\mathrm{FeSO}_{4}$

In general, the harvesting of algal biomass using chemical flocculants occurs through one of the following possible mechanisms: charge neutralization, electrostatic patching, bridging, or sweeping. ${ }^{13}$ The formation of a positively charged metal hydroxide takes place upon the solubilization of $\mathrm{FeSO}_{4}$ in water. In the present study, the $\mathrm{pH}$ of the algal culture broth after the addition of $\mathrm{FeSO}_{4}$ was observed to decrease from 8.47
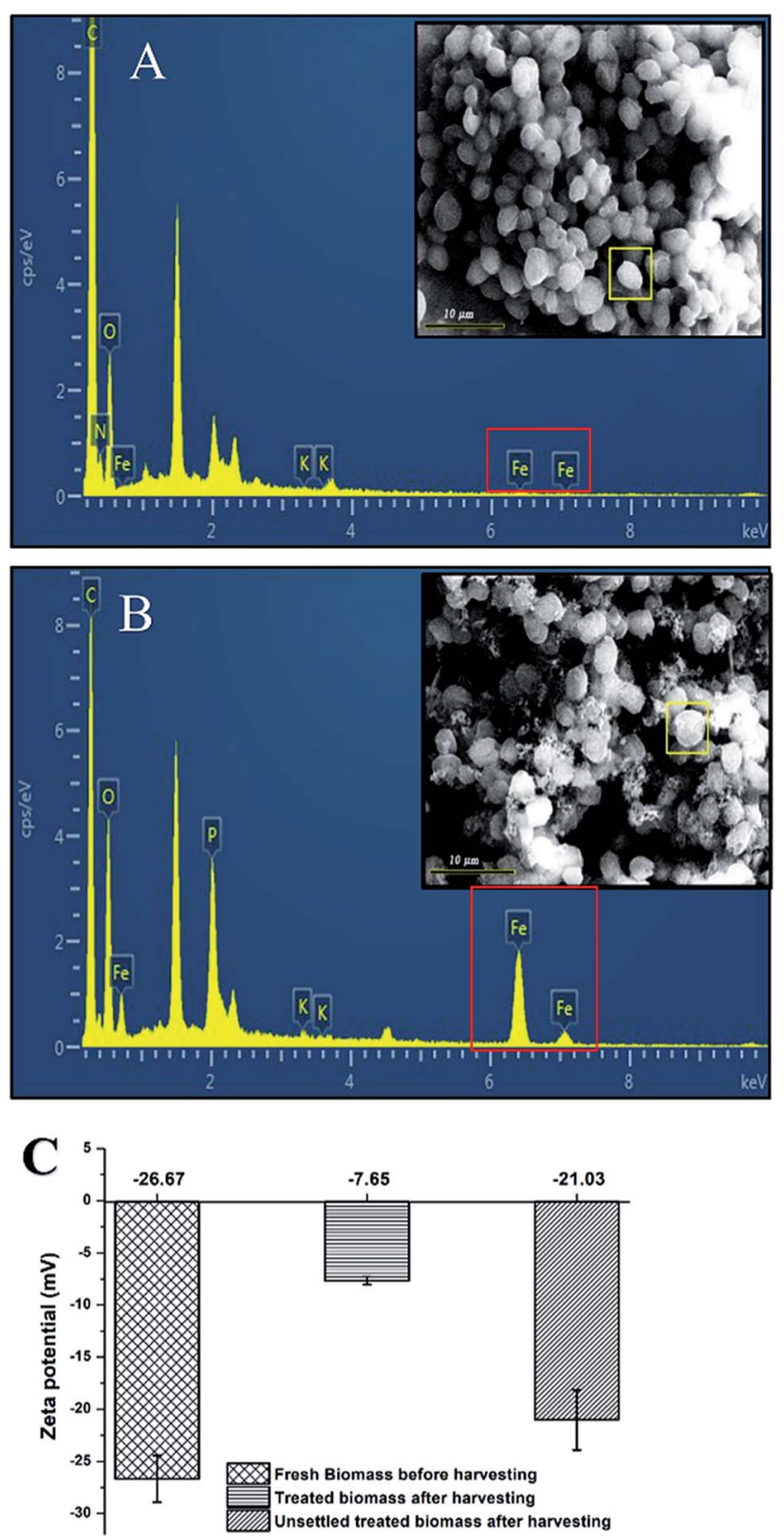

Fig. 5 Characteristics of Chlorella sp. FC2 cell morphology revealed by SEM/EDX: (A) before flocculation; (B) after flocculation using $\mathrm{FeSO}_{4}$. (C) Zeta potential of the microalgal culture for the fresh biomass before harvesting, treated biomass after harvesting, and treated nonflocculated biomass after harvesting. The harvesting experiment was carried out at an F/X ratio of 2.5 and harvesting time of $50 \mathrm{~min}$. to 5.52. This significant drop in the $\mathrm{pH}$ of the culture broth indicates the formation of $\mathrm{Fe}(\mathrm{OH})_{2}{ }^{+}$or $\mathrm{Fe}(\mathrm{OH})^{2+} \cdot{ }^{32}$ These cations are then attracted towards the negatively charged cell surface of FC2, resulting in the formation of larger flocs (Fig. 5A and B), and this might be due to charge neutralization. The mechanism of charge neutralization was further examined in the context of the possible attachment of the positively charged metal ions to the negatively charged biomass through the SEM-EDX profile (Fig. 5A and B). The phenomenon of charge neutralization was prominently reflected in the zeta potential data obtained for three conditions: fresh biomass before harvesting, treated biomass after harvesting, and spent water with treated nonflocculated biomass after harvesting. The highest zeta potential of $-26.67 \mathrm{mV}$ was obtained for the fresh biomass, depicting the instability of the cells in the suspension (Fig. 5C). A significant reduction in the zeta potential to a value of $-7.65 \mathrm{mV}$ was obtained for the harvested FC2 cells, suggesting charge neutralization and contribution to the flocculation of the FC2 cells (Fig. 5C).

\section{Demonstration of a low-cost harvesting method at the scaled- up conditions of a $5 \mathrm{~L}$ photobioreactor and $500 \mathrm{~L}$ open raceway pond}

In the present study, a low-cost harvesting technology was developed for the FC2 cells by (i) employing a cheaper commercial grade flocculant and (ii) recycling the nutrient-rich spent water for the growth of the FC2 cells. With the aim of establishing the application feasibility of the harvesting process at different scales of operation, the harvesting experiments were performed with the biomass grown in a $5 \mathrm{~L}$ automated photobioreactor under indoor conditions with the optimized $F / X$ ratio of 2.5 (the RWHC batch). Furthermore, harvesting experiments were also performed with a lower $F / X$ ratio of 1.5 (the RWNFC batch). This lower $F / X$ ratio was considered with the primary objective of achieving economic feasibility through (i) lower flocculant loading and (ii) bypassing the requirement of separate inoculum development. It is important to note that one of the key features of the present harvesting method is that it not only enables the recycling of spent water, but also enables the treated non-flocculated FC2 cells to be used as an inoculum. In general, an inoculum size in the range of $10-15 \%(v / v)$ has been used for large-scale cultivation. In the present study, 10\% inoculum was used for all the experiments, resulting in an average initial biomass concentration of $0.1-0.2 \mathrm{~g} \mathrm{~L}^{-1}$. The optimum $F / X$ ratio of 2.5 resulted in a harvesting efficiency of $96 \%$, resulting in a non-flocculated biomass concentration of $0.04 \mathrm{~g} \mathrm{~L}^{-1}$ in the spent water. This requires the supplementation of fresh inoculum for the successive batch. However, an $F / X$ ratio of 1.5 with a harvesting efficiency of $\sim 80 \%$ resulted in a biomass concentration of $\sim 0.2 \mathrm{~g} \mathrm{~L}^{-1}$ in the spent water, hence circumventing the need for the supplementation of fresh inoculum.

In the case of the $5 \mathrm{~L}$ photobioreactor with an $F / X$ ratio of 2.5, the first RWHC batch resulted in a biomass productivity of $349.9 \mathrm{mg} \mathrm{L}^{-1}$ day $^{-1}$, which was found to be comparable with that of the control batch (376.1 $\mathrm{mg} \mathrm{L}^{-1}$ day $^{-1}$ ) (Fig. 6, Panel A). A 


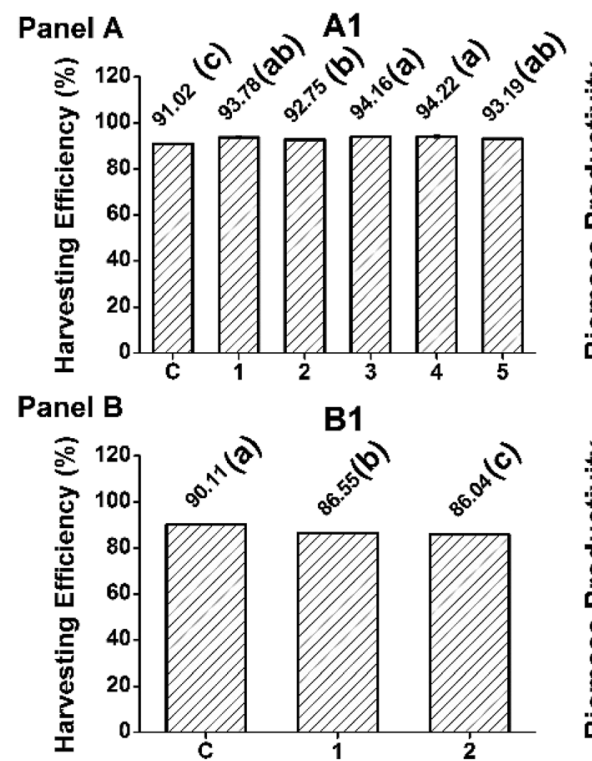

Panel C

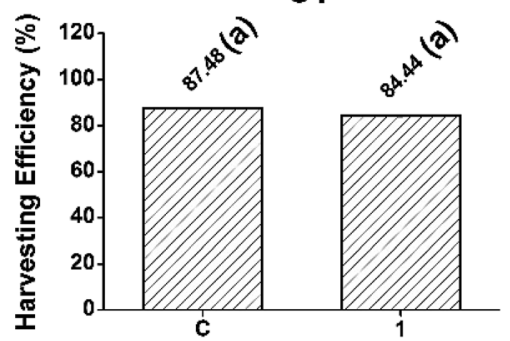

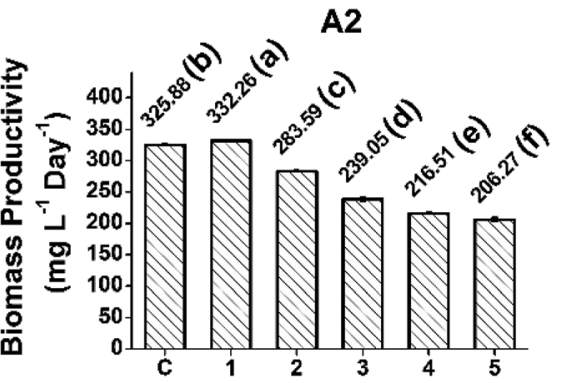

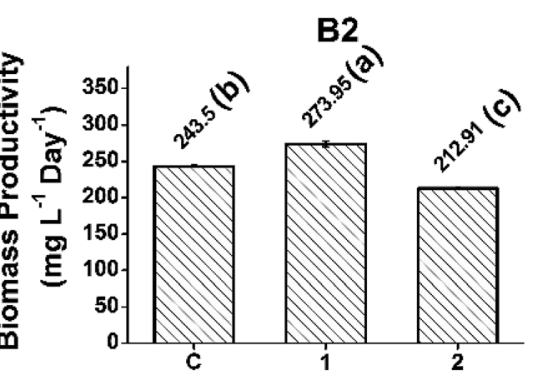

C2

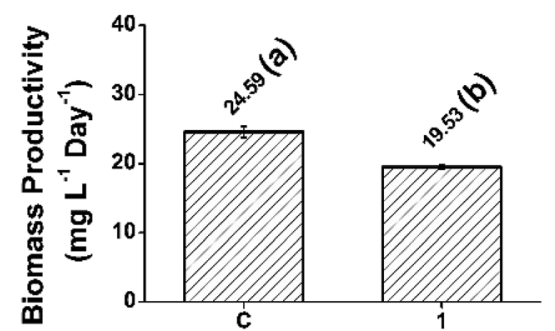

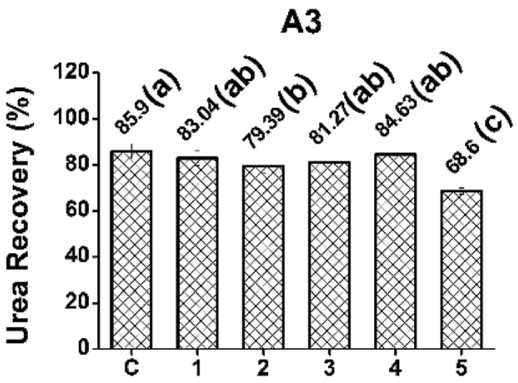

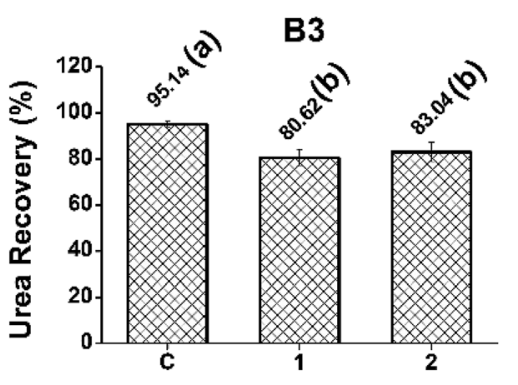

C3

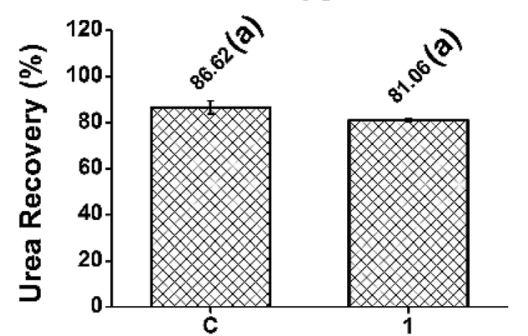

Fig. 6 Effect of recycling of post-harvested spent water on the harvesting efficiency, biomass productivity and urea recovery for the growth of Chlorella sp. FC2 flocculated by $\mathrm{FeSO}_{4}$. Panel A: the FC2 cells were grown in a $5 \mathrm{~L}$ photobioreactor, followed by biomass harvesting with an $\mathrm{F} / \mathrm{X}$ ratio of 2.5. Six consecutive batches of cultivation were performed (one control batch (C), followed by five RWHC batches (1-5)). Panel B: the FC2 cells were grown in a $5 \mathrm{~L}$ photobioreactor, followed by biomass harvesting with an $F / X$ ratio of 1.5 . Three consecutive batches of cultivation were performed (one control batch (C), followed by two RWNFC batches (1-2)). Panel C: the FC2 cells were grown in a $350 \mathrm{~L}$ open raceway pond, followed by biomass harvesting with an F/X ratio of 1.5. Two consecutive batches of cultivation were performed (one control batch (C), followed by one RWNFC batch (1)). The letters on the bar graphs represent the significant difference between the harvesting efficiency, biomass productivity, and urea recovery obtained from harvesting microalgal biomass using $\mathrm{FeSO}_{4}$ analyzed using the one-way analysis of variance based on Tukey's method. Harvesting efficiency, biomass productivity and urea recovery that do not share a common letter are significantly different.

marginal decline in the biomass productivity $\left(325.7 \mathrm{mg} \mathrm{\textrm {L } ^ { - 1 }}\right.$ day $^{-1}$ ) was observed for the second RWHC batch, followed by a gradual decrease to $218.7 \mathrm{mg} \mathrm{L}^{-1}$ day $^{-1}$ in the fifth RWHC batch. A marginally inferior average urea recovery of $79.3 \%$ was recorded for the RWHC batches when compared with that of the control (85.9\%) (Fig. 6, Panel A). However, the harvesting efficiency was found to be similar for all six batches. Upon scaling up the harvesting technology to the $5 \mathrm{~L}$ photobioreactor, both the average harvesting efficiency $(93.6 \%)$ and average urea recovery $(79.3 \%)$ in the case of the RWHC batches were found to be similar to the corresponding values achieved for the $350 \mathrm{~mL}$ mini-reactor (Fig. 6, Panel A). The biomass productivities of the FC2 cells in the five successive $5 \mathrm{~L}$ RWHC batches were found to be similar to those of the $350 \mathrm{~mL}$ RWHC batches when compared with the values for their respective control batches (Fig. 6, Panel A). Interestingly, even with a lower flocculant loading $(F / X=1.5)$, the average biomass productivity, urea recovery, and harvesting efficiency achieved in the RWNFC batches remained uncompromised when compared with those for the RWHC batches with an $F / X$ ratio of 2.5 (Fig. 6, Panel B). Fig. S3 and S4 $\uparrow$ illustrate the dynamic growth profiles in the control and recycle batches for the $F / X$ ratios of 2.5 and 1.5, respectively (ESI). Finally, in order to validate the present harvesting technology at a much larger scale and under different growth conditions, FC2 was cultivated in a $350 \mathrm{~L}$ open raceway pond under outdoor conditions with an $F / X$ ratio of 1.5 for two consecutive batches (one control batch and one RWNFC batch). For the dynamic growth profile, please refer to Fig. S5, ESI. $\uparrow$ In the case of the open raceway pond, the harvesting efficiency and urea recovery for the RWNFC batch were found to be similar to those of the control batch (Fig. 6, Panel C). Nevertheless, the biomass productivity was observed to be compromised in the case of RWNFC (Fig. 6, Panel C), which may be due to the fluctuation in the growth parameters under outdoor conditions and not due to any detrimental effect of the flocculant, as explained in the previous section. It is interesting to note that due to the higher flocculant loading in the case of the $F / X$ ratio of 2.5 , the spent water turned acidic with a $\mathrm{pH}$ value in the range 
of 3.16-5.59. A similar reduction in the $\mathrm{pH}$ of the post-harvested spent water was observed in the case of the $350 \mathrm{~mL}$ mini-reactor and $5 \mathrm{~L}$ photobioreactor. This necessitated the adjustment of the spent water $\mathrm{pH}$ to a value of 7-7.4 via the addition of $1 \mathrm{~N}$ $\mathrm{NaOH}$, which in turn incurred additional raw material cost. However, the harvesting of biomass with an $F / X$ ratio of 1.5 resulted in a neutral $\mathrm{pH}$ of the spent water, eradicating the need of $\mathrm{pH}$ adjustment, which further boosted the process economy. The results suggest the feasibility of the present low-cost harvesting technology from the point of view of its scale-up under different cultivation conditions.

\section{Analysis of biomass harvesting cost}

In order to evaluate the harvesting cost, a detailed cost analysis was carried out for the cultivation of FC2 in a $350 \mathrm{~L}$ open raceway pond with $F / X=1.5$ (Table $\mathrm{S} 1$, ESI $\dagger$ ). Depending on the variation in the market price of commercial grade $\mathrm{FeSO}_{4}$, the harvesting cost of $1 \mathrm{~kg}$ biomass was estimated to be in the range of 0.17-0.3 USD, while for analytical grade $\mathrm{FeSO}_{4}$, the harvesting cost significantly increased to 18.33 USD. Furthermore, the cost of harvesting $1 \mathrm{~kg}$ of microalgal biomass using commercial grade $\mathrm{FeSO}_{4}$ obtained in the present study was found to be lower than those reported for other harvesting studies using analytical grade chemicals (Table 1). Harvesting Chlamydomonas reinhardtii using commercial grade polyaluminium chloride resulted in a much lower harvesting cost of 0.077 USD per $\mathrm{kg}$ of biomass. ${ }^{18}$ However, in this study, an evaluation of the harvesting cost was carried out at a much lower scale of $500 \mathrm{~mL}$ and only the flocculant cost was considered. In the present study, the harvesting cost was estimated at a much larger scale of $20 \mathrm{~L}$, and both the cost of the flocculant and power consumption for mixing were taken into account. This clearly demonstrates the advantage of using commercial grade $\mathrm{FeSO}_{4}$ over analytical grade $\mathrm{FeSO}_{4}$ as it offers better economic feasibility.

\section{Conclusions}

In the present study, a low-cost and scalable process was developed for harvesting microalgal biomass using chemical flocculation. The potentially higher cost of harvesting was curtailed by using cheaper commercial grade chemicals, which resulted in the harvesting efficiency (87.48-99.09\%) being similar to that achieved with analytical grade chemicals (92.3\%). Furthermore, nutrient-rich spent water and microalgal cells post-harvesting were recycled for five successive batches, which resulted in better process economy. The scale-up feasibility of the developed low-cost harvesting method was demonstrated with a $5 \mathrm{~L}$ automated photobioreactor under indoor conditions and a $350 \mathrm{~L}$ open raceway pond under outdoor conditions. Microscopic analysis and flow cytometry analysis revealed no detrimental effect of $\mathrm{FeSO}_{4}$ on the cell morphology and cell viability. The harvesting cost of $1 \mathrm{~kg}$ biomass using commercial grade $\mathrm{FeSO}_{4}$ was estimated to be in the range of 0.17-0.3 USD and was significantly lower as compared to that of analytical grade $\mathrm{FeSO}_{4}$ (18.33 USD).

\section{Conflicts of interest}

There are no conflicts to declare.

\section{Acknowledgements}

The authors gratefully acknowledge the financial support of the Oil and Natural Gas Corporation Ltd, India. G. Goswami is thankful to the Science and Engineering Research Board, India (NPDF, File No. PDF/2015/000841). We are grateful to Prof. Latha Rangan for providing us with the Coulter Epics XL4 flow cytometer.

\section{References}

1 M. K. Weschler, W. J. Barr, W. F. Harper and A. E. Landis, Bioresour. Technol., 2014, 153, 108-115.

2 A. Milbrandt and E. Jarvis, Resource Evaluation and Site Selection for Microalgae Production in India, NREL/TP-6A248380, National Renewable Energy Laboratory, 2010.

3 A. I. Barros, A. L. Gonçalves, M. Simões and J. C. M. Pires, Renewable Sustainable Energy Rev., 2015, 41, 1489-1500.

4 J. Doucha and K. Lívanský, J. Appl. Phycol., 2006, 18, 811-826.

5 C. Y. Chen, K. L. Yeh, R. Aisyah, D. J. Lee and J. S. Chang, Bioresour. Technol., 2011, 102, 71-81.

6 A. Guldhe, R. Misra, P. Singh, I. Rawat and F. Bux, Algal Res., 2016, 19, 292-298.

7 K. Gharat, A. Agarwal, R. A. Pandit and A. M. Lali, Bioresource Technology Reports, 2018, 4, 193-201.

8 J. Roostaei, Y. Zhang, K. Gopalakrishnan and A. J. Ochocki, Sci. Rep., 2018, 8, 12528.

9 A. S. Japar, M. S. Takriff, N. Haiza and M. Yasin, Biochem. Pharmacol., 2016, 5, 555-563.

10 T. Mathimani and N. Mallick, Renewable Sustainable Energy Rev., 2018, 91, 1103-1120.

11 S. B. Ummalyma, A. K. Mathew, A. Pandey and R. K. Sukumaran, Bioresour. Technol., 2016, 213, 216-221.

12 L. Christenson and R. Sims, Biotechnol. Adv., 2011, 29, 686702.

13 D. Vandamme, I. Foubert and K. Muylaert, Trends Biotechnol., 2013, 31, 233-239.

14 A. Pandey, V. V. Pathak, R. Kothari, P. N. Black and V. V. Tyagi, J. Environ. Manage., 2019, 231, 562-569.

15 N. Uduman, Y. Qi, M. K. Danquah, G. M. Forde and A. Hoadley, J. Renewable Sustainable Energy, 2010, 2, 012701.

16 E. Molina Grima, E. H. Belarbi, F. G. Acién Fernández, A. Robles Medina and Y. Chisti, Biotechnol. Adv., 2003, 20, 491-515.

17 N. Pragya, K. K. Pandey and P. K. Sahoo, Renewable Sustainable Energy Rev., 2013, 24, 159-171.

18 F. Delrue, Y. Imbert, G. Fleury, G. Peltier and J. F. Sassi, Algal Res., 2015, 9, 283-290.

19 F. Roselet, D. Vandamme, M. Roselet, K. Muylaert and P. C. Abreu, BioEnergy Res., 2017, 10, 427-437.

20 M. Singh, R. Shukla and K. Das, Biotechnol. Appl. Microalgae, 2013, 77-87. 
21 M. Muthuraj, V. Kumar, B. Palabhanvi and D. Das, J. Ind. Microbiol. Biotechnol., 2014, 41, 499-511.

22 M. Muthuraj, N. Chandra, B. Palabhanvi, V. Kumar and D. Das, BioEnergy Res., 2015, 8, 726-739.

23 E. S. Salama, B. H. Jeon, M. B. Kurade, R. A. I. Abou-Shanab, S. P. Govindwar, S. H. Lee, I. S. Yang and D. S. Lee, Energy Convers. Manage., 2016, 121, 105-112.

24 R. Prado, C. Rioboo, C. Herrero and Á. Cid, Aquat. Toxicol., 2011, 102, 10-17.

25 D. R. Wybenga, J. Di Giorgio and V. J. Pileggi, Clin. Chem., 1971, 17, 891-895.

26 T. R. Parsons, Y. Maita and C. M. Lalli, Determination of Phosphate, A Manual of Chemical and Biological Methods for Seawater Analysis, 1984, pp. 22-25.

27 L. Chen, C. Wang, W. Wang and J. Wei, Bioresour. Technol., 2013, 133, 9-15.

28 M. D. Scherer, F. J. C. M. Filho, A. C. Oliveira, N. F. H. Selesu, C. M. L. Ugaya, A. B. Mariano and J. V. C. Vargas, J. Environ. Sci. Health, Part A: Toxic/Hazard. Subst. Environ. Eng., 2018, 53, 938-945.
29 P. Gani, N. Mohamed Sunar, H. Matias-Peralta and A. A. Abdul Latiff, Int. J. Green Energy, 2017, 14, 395-399.

30 J. F. Reyes and C. Labra, Biomass Bioenergy, 2016, 87, 78-83. 31 Y. Avnimelech, B. W. Troeger and L. W. Reed, Science, 1982, 216, 63-65.

32 N. B. Wyatt, L. M. Gloe, P. V. Brady, J. C. Hewson, A. M. Grillet, M. G. Hankins and P. I. Pohl, Biotechnol. Bioeng., 2012, 109, 493-501.

33 V. M. Rwehumbiza, R. Harrison and L. Thomsen, Chem. Eng. J., 2012, 200-202, 168-175.

34 W. Farooq, M. Moon, B. gon Ryu, W. I. Suh, A. Shrivastav, M. S. Park, S. K. Mishra and J. W. Yang, Algal Res., 2015, 8, $1-7$.

35 Y. Xu, S. Purton and F. Baganz, Bioresour. Technol., 2013, 129, 296-301.

36 A. Papazi, P. Makridis and P. Divanach, J. Appl. Phycol., 2010, 22, 349-355.

37 S. Şirin, R. Trobajo, C. Ibanez and J. Salvadó, J. Appl. Phycol., 2012, 24, 1067-1080.

38 S. Koley, S. Prasad, S. K. Bagchi and N. Mallick, RSC Adv., 2017, 7, 7227-7237. 